\title{
Estimasi Kondisi Muatan dan Kondisi Kesehatan Baterai VRLA dengan Metode RVP
}

\author{
(Estimation of VRLA Batery's SOC and SOH Using SVR Method)
}

\author{
Danang Widjajanto ${ }^{1}$, Beny Maulana Achsan ${ }^{2}$, Fajar Muhammad Noor Rozaqi ${ }^{3}$, Augie Widyotriatmo ${ }^{4}$, Edi Leksono ${ }^{5}$
}

\begin{abstract}
Optimization of battery usage, including VRLA battery which is often used for large amounts of energy storage at low prices, is usually pursued by implementing Battery Management System (BMS). To carry out BMS, information about the condition of charge and health is needed. The State of Charge (SoC) is defined as the ratio of the current remaining capacity of the battery to the capacity of the battery before discharge, while the State of Health ( $\mathrm{SoH})$ is the ratio between the measured full capacity of a battery to its nominal capacity when it is still in a new condition. SoC and SoH estimation can be held indirectly by using the voltage and current at the battery terminals. This study uses the Coulomb Counting (CC) method and Support Vector Regression (SVR) to estimate SoC and SoH of VRLA batteries which are used as backup energy for the nanogrid system in the laboratory. This study uses a Python machine learning module which enables the implementation of SVR with various types of kernels including linear kernels, polynomial kernel, and RBF kernel. The tests carried out in this research using the grid search module show that the best performance is obtained when using the RBF kernel.
\end{abstract}

Intisari-Optimalisasi penggunaan baterai, termasuk baterai VRLA yang sering digunakan untuk keperluan penyimpanan energi dalam jumlah besar dengan harga yang rendah, biasa diupayakan dengan menyelenggarakan Sistem Manajemen Baterai (SMB). Untuk melakukan SMB, dibutuhkan informasi tentang Kondisi Muatan (KM) dan Kondisi Kesehatan (KK) baterai. KM didefinisikan sebagai rasio kapasitas sisa baterai saat ini dengan kapasitas baterai sebelum pengosongan, sedangkan KK baterai ialah rasio antara kapasitas penuh terukur terhadap kapasitas nominalnya pada saat baterai masih dalam keadaan baru beroperasi. Yang menjadi permasalahan, kedua informasi tersebut tidak dapat diukur secara langsung. Estimasi KM dan KK dapat dilakukan secara tidak langsung dengan menggunakan parameter-parameter yang mudah diukur, terutama tegangan dan arus pada terminal baterai. Makalah ini menggunakan metode Coulomb Counting (CC) dan Regresi Vektor Pendukung (RVP) untuk mengestimasi KM dan KK baterai VRLA yang digunakan sebagai energi cadangan sistem nanogrid yang ada di laboratorium. Makalah ini menggunakan modul mesin pembelajaran Python yang memungkinkan implementasi RVP dengan berbagai jenis kernel, di antaranya kernel linear, kernel polinomial, dan kernel RBF. Pengujian yang dilakukan

1,2,3,4,5 Program Studi Teknik Fisika, Institut Teknologi Bandung; Gedung TP Rachmat (Labtek VI) Jl. Ganesa No.10 Bandung 40132, Indonesia. (tlp: 022250 4424; fax: 022250 6281; email: ${ }^{1}$ danang.pgrad@students.itb.ac.id, 213315025@students.itb.ac.id, ${ }^{3} 13315009 @$ students.itb.ac.id, $\left.{ }^{5} e d i @ t f . i t b . a c . i d\right)$ menggunakan modul grid search menunjukkan bahwa kinerja terbaik diperoleh ketika menggunakan kernel RBF.

Kata Kunci-Baterai VRLA, RVP, Kondisi Muatan, Kondisi Kesehatan, Coulomb Counting.

\section{PENDAhuluan}

Kebutuhan untuk menyimpan energi listrik agar dapat digunakan pada saat keadaan membutuhkan merupakan hal yang semakin penting dari waktu ke waktu. Saat ini tersedia berbagai teknologi untuk menyimpan energi listrik, seperti baterai, sel bahan bakar (fuel-cell), pumped hydro storage, flywheel, underground thermal, compressed air, super capacitor energy storage, dan superconducting magnetic energy storage. Namun, hingga saat ini baterai masih merupakan teknologi yang paling praktis untuk digunakan pada berbagai ragam kebutuhan penyimpanan energi [1].

Salah satu aplikasi teknologi baterai adalah sebagai penyedia energi cadangan (backup energy) pada sistem nanogrid, seperti yang dilakukan di Laboratorium Manajemen Energi TF - ITB yang menjadi objek pada makalah ini. Nanogrid adalah microgrid dalam skala kecil, yaitu kapasitasnya tidak lebih dari $10 \mathrm{kWatt}$. Microgrid sendiri adalah sistem distribusi tenaga listrik otonom untuk komunitas kecil yang memanfaatkan pembangkit yang sifatnya lokal dan umumnya menggunakan sumber energi terbarukan yang dapat memberikan berbagai keuntungan. Berbagai keuntungan yang dapat diperoleh dari penerapan konsep microgrid, seperti peningkatan keandalan, efisiensi, penghematan biaya pembangkitan, dan ramah lingkungan, menyebabkan penetrasinya ke sistem tenaga listrik meningkat dari hari ke hari [2].

Sistem penyimpan energi memiliki peran yang sangat penting pada sistem nanogrid/microgrid. Salah satu kelebihan sistem nanogrid adalah kemampuannya untuk mempergunakan sumber energi terbarukan yang biayanya sangat murah, seperti energi matahari dan angin. Namun, energi terbarukan memiliki kekurangan yaitu tidak selalu tersedia pada saat diperlukan (bersifat intermittent). Contohnya, energi matahari hanya ada pada siang hari. Pada sistem nanogrid, kekurangan sifat intermittent pada sumber energi terbarukan dapat diatasi dengan menyertakan sistem penyimpan energi dalam sistem. Misalnya, pada siang hari energi yang berasal dari sinar matahari yang berlebih dapat disimpan untuk kemudian dapat digunakan pada malam hari ketika energi matahari tidak tersedia.

Jenis baterai yang digunakan pada sistem nanogrid di Laboratorium Manajemen Energi adalah baterai Valve Regulated Lead Acid (VRLA). Baterai jenis ini merupakan 
pengembangan dari baterai asam timbal (Lead Acid/LA) yang biasa. Baterai LA merupakan jenis baterai sekunder yang paling dahulu ditemukan sebelum ditemukannya baterai sekunder jenis yang lain. Baterai sekunder adalah istilah yang digunakan untuk baterai yang dapat diisi ulang, sedangkan baterai yang hanya digunakan sekali pakai biasa dinamakan baterai primer. Selain baterai LA, saat ini telah ditemukan beberapa jenis baterai sekunder yang lain, seperti baterai lithium-ion, baterai nickel cadmium, dan baterai Li-polymer, dengan kelebihan dan kekurangannya masing-masing [3]. Umumnya, penamaan baterai didasarkan pada material kimia yang menjadi penyusun utamanya. Kelebihan baterai VRLA dibandingkan baterai LA biasa terletak pada kemudahan perawatannya. Hal ini disebabkan baterai ini bersifat tertutup (sealed) sehingga penguapan yang terjadi sangat kecil, yang menyebabkan tidak diperlukannya penambahan cairan selama masa pemakaian sehingga sangat memudahkan perawatan [4].

Pengelolaan sistem penyimpan energi baterai yang dikenal dengan nama Sistem Manajemen Baterai (SMB) bertugas memantau, mengatur, dan menjaga baterai agar dapat beroperasi secara optimal dan mencegah terjadinya kondisikondisi yang dapat merusak baterai. Salah satu indikator yang sangat penting pada SMB adalah Kondisi Muatan (KM) atau disebut juga dengan State of Charge (SoC) dan Kondisi Kesehatan (KK) atau disebut juga sebagai State of Health (SoH). Informasi tentang KM dan KK sangat dibutuhkan oleh SMB dalam pelaksanaan tugasnya [5]. Satu hal yang menjadi permasalahan adalah kedua informasi tersebut tidak dapat diukur secara langsung. Namun, estimasi KM dan KK dapat dilakukan secara tidak langsung. Saat ini telah ada berbagai metode estimasi KM dan KK yang dapat digunakan. Beberapa metode di antaranya telah sangat dikenal dan digunakan secara luas dan beberapa metode masih berada dalam tahapan riset dan belum digunakan untuk keperluan riil [6], [7].

Referensi [8] meninjau metode-metode yang dapat digunakan untuk mengestimasi KM pada baterai LA. Metode yang mengorelasikan tegangan dengan KM mudah untuk dikerjakan, tetapi tingkat akurasinya rendah dikarenakan galat yang disebabkan kompensasi impedans. Metode yang sudah terbukti berhasil diimplementasikan adalah metode integrasi arus atau metode Coulomb Counting (CC). Penggabungan metode integrasi arus dengan korelasi tegangan dipandang sebagai metode yang lebih baik. Pada penelitian lain, diusulkan metode estimasi KM pada baterai LA menggunakan algoritme mesin pembelajaran Artificial Neural Network (ANN) dengan tingkat akurasi yang cukup baik [9]. Validasi dilakukan dengan mengimplementasikan metode ini pada satu sel baterai LA yang sepenuhnya terkontrol di laboratorium. Referensi [10] mencoba melakukan estimasi KM pada baterai LA menggunakan algoritme mesin pembelajaran Regresi Vektor Pendukung (RVP). Validasi metode estimasi dilakukan dengan menggunakan data simulasi dari sebuah sel baterai LA 4 V, 4,5 Ah yang dibangkitkan dengan menggunakan program Simulink dari MATLAB.

Referensi [6] mengkaji berbagai metode estimasi KM dan menggolongkannya menjadi empat kelompok, yaitu metode pengukuran langsung (direct measurement), metode book- keeping, metode adaptif, dan metode gabungan (hybrid). Hasil kajian menjelaskan kelebihan dan kekurangan masing-masing metode yang ada. Referensi [11] mempelajari metode estimasi KM pada baterai yang digunakan pada sistem microgrid dalam rangka meningkatkan kinerjanya. Menurut penelitian ini, metode atau model untuk mengestimasi KM baterai pada sistem microgrid dapat digolngkan menjadi empat kelompok, yaitu metode pengukuran langsung, metode kecerdasan buatan (artificial intelligence method), metode berbasis model (modelbased method) dan metode gabungan (hybrid). Referensi [7] juga secara komprehensif mempelajari berbagai parameter kondisi baterai yang dapat sangat berguna dalam operasional $\mathrm{SMB}$, di antaranya adalah KM, KK, state of energy (SoE), dan Sisa Waktu Guna/SWG (Remaining Useful Life/RUL). Sementara itu, telah diusulkan juga metode estimasi KM dan KK pada baterai lithium-ion secara daring dengan menggunakan parameter pengukuran terbaru yang dinamakan unit time voltage drop (V') yang merepresentasikan penurunan tegangan per satuan waktu pada saat proses pengosongan [12].

Mengacu pada tinjauan pustaka di atas, dapat dilihat bahwa ada cukup banyak metode yang dapat digunakan untuk melakukan estimasi KM baterai dan juga estimasi KK karena ada kaitan yang sangat erat antara KK dengan KM baterai. Berdasarkan tinjauan pustaka yang dilakukan, diketahui bahwa sebagian besar data yang digunakan pada penelitian terdahulu adalah data baterai yang berasal dari hasil simulasi atau data yang berasal dari baterai yang sepenuhnya dapat dikontrol di laboratorium. Makalah ini mencoba mengimplementasikan metode estimasi KM dan KK berbasis data, yaitu metode mesin pembelajaran RVP dengan menggunakan data riil yang berasal dari sistem penyimpan energi baterai yang tersusun dari seperangkat sel baterai VRLA yang disusun secara khusus untuk menjadi bagian penting dari sistem nanogrid yang ada di Laboratorium Manajemen Energi TF - ITB. Makalah ini ingin membuktikan bahwa penerapan algoritme mesin pembelajaran RVP mampu menghasilkan model regresi yang dapat digunakan untuk mengestimasi nilai $\mathrm{KM}$ dengan tingkat akurasi yang lebih baik dibandingkan metode konvensional, yaitu dengan metode $\mathrm{CC}$, ketika diimplementasikan pada sistem yang riil.

Makalah ini disusun menjadi empat bagian, yaitu 1) pendahuluan, yang berisi latar belakang penelitian, tujuan penelitian, tinjauan literatur, dan kontribusi yang diberikan oleh penelitian ini; 2) metodologi, yang memuat tahapan-tahapan yang dilakukan, dasar teori, dan konfigurasi peralatan yang digunakan pada penelitian ini; 3) hasil dan pembahasan, yang memaparkan hasil yang didapatkan pada penelitian ini berserta analisisnya; serta 4) kesimpulan penelitian.

\section{Metodologi}

Pengukuran kondisi muatan baterai tidak mudah dilakukan karena reaksi yang terjadi dalam proses pengisian dan pengosongan sebuah baterai adalah reaksi kimia yang cukup kompleks. Parameter baterai yang paling mungkin untuk diukur adalah tegangan, arus, dan temperatur baterai. Karena hal ini, ketiga parameter tersebut sering dijadikan indikator untuk mengestimasi KK dan KK baterai. Berbagai cara untuk 
melakukan estimasi KM baterai telah dikembangkan oleh para ahli. Secara umum, terdapat empat metode untuk mengestimasi KM baterai, yaitu metode pengukuran langsung, metode book keeping, metode mesin pembelajaran, dan metode gabungan.

Metode pertama adalah metode pengukuran langsung. Metode pengukuran langsung merujuk pada properti fisis baterai seperti tegangan terminal dan impedans baterai untuk mengestimasi KM baterai. Salah satu metode pengukuran langsung adalah metode tegangan sirkuit terbuka. Pada metode ini, KM baterai diestimasi dengan pendekatan tegangan sirkuit terbuka. Secara matematis, estimasi KM baterai dengan metode tegangan sirkuit terbuka dapat dilihat pada (1), dengan $V s t(t)$ menyatakan tegangan sirkuit terbuka pada saat $t, K M(t)$ menyatakan kondisi muatan baterai pada saat $t, a_{0}$ menyatakan tegangan terminal baterai saat $K M=0$, serta $a_{1}$ didapat dengan mengetahui nilai $a_{0}$ dan $V s t(t)$ saat $K M=1$ [13]. Kelemahan metode ini adalah pada saat pengukuran, semua beban harus dilepaskan.

$$
V_{s t}(t)=a_{1} * K M(t)+a_{0} .
$$

Metode estimasi KM baterai kedua adalah metode bookkeeping. Metode ini memperhitungkan beberapa efek internal baterai, seperti self-discharge, peluruhan kapasitas, dan efisiensi pengosongan dalam mengestimasi KM baterai. Salah satu metode book-keeping yang paling populer adalah metode CC. Pada metode CC, KM baterai diestimasi dengan mengukur arus pengosongan dan mengintegrasikannya terhadap waktu [13]. Secara matematis, estimasi KM baterai dengan metode CC dituliskan pada (2), dengan $K M(t)$ menyatakan KM baterai pada waktu $t, K M(t-1)$ menyatakan $\mathrm{KM}$ baterai sebelum waktu $t, I(t)$ menyatakan arus pengosongan baterai pada waktu $t$, dan $C_{\mathrm{o}}$ menyatakan kapasitas baterai sebelum pengosongan dalam Ah.

$$
K M(t)=K M(t-1)-\frac{1}{C_{o}} \int_{t-1}^{t} I(t) d t
$$

Metode ketiga yaitu metode sistem adaptif. Metode sistem adaptif adalah metode yang dapat menyesuaikan secara otomatis terhadap perubahan sistem. Pada dasarnya, baterai bekerja secara kimia dengan melibatkan proses kimia yang kompleks. Hal ini menyebabkan sifat KM baterai tidak linear. Sistem adaptif menawarkan solusi yang baik untuk mengestimasi KM baterai. Salah satu metode sistem adaptif adalah metode RVP. Estimasi dengan MVP tidak hanya menghilangkan kelemahan dari metode $\mathrm{CC}$, tetapi juga dapat menghasilkan prediksi yang lebih akurat. Untuk mengimplementasikan metode RVP pada kasus estimasi KM dan KK pada makalah ini, dipilih bahasa pemrograman Python dengan memanfaatkan modul scikit-learn sebagai modul algoritme mesin pembelajarannya.

Penelitian dalam makalah ini dapat dibagi menjadi dua bagian, yaitu estimasi KM dan estimasi KK baterai. Alur kedua bagian penelitian tersebut ditunjukkan pada Gbr. 1 .

Penelitian ini diawali dengan pengambilan data dari basis data Laboratorium Manajemen Energi TF - ITB. Data yang telah diambil selanjutnya dipisah menjadi dua, yaitu data pengukuran untuk estimasi KM (Tahap 1) dan data historis untuk estimasi KK (Tahap 2).

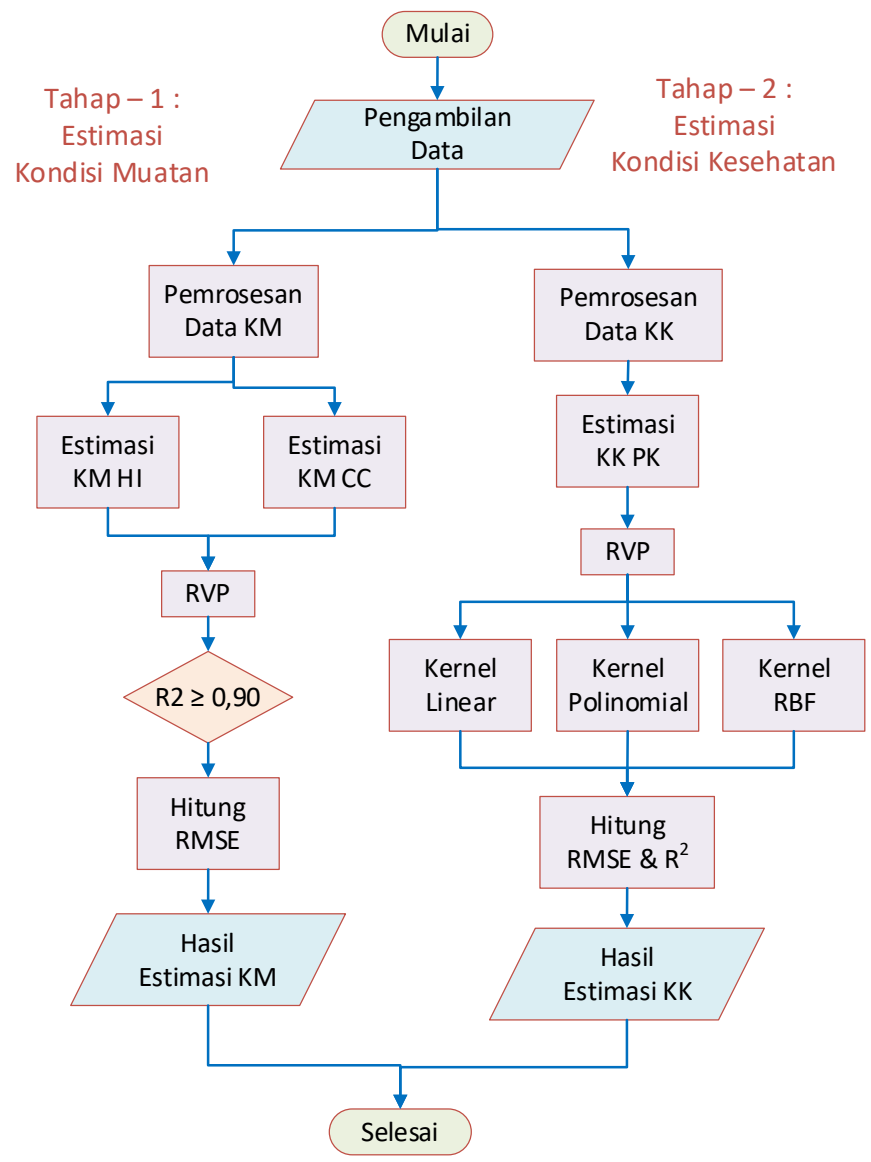

Gbr. 1 Alur pelaksanaan penelitian.

\section{A. Penelitian Tahap 1}

Pada tahap 1 ini dilakukan pemrosesan awal untuk memisahkan data latih dan data uji. Data latih adalah data estimasi KM baterai pembacaan Hybrid Inverter (HI) dan hasil perhitungan estimasi KM baterai dengan metode CC. Kedua data latih tersebut digunakan sebagai masukan untuk estimasi KM baterai dengan metode RVP. Pada metode RVP, dicari nilai parameter C, gamma, dan epsilon optimum berdasarkan skor uji rata-rata. Kombinasi parameter RVP dengan skor uji rata-rata tertinggi dipilih untuk diterapkan pada model. Selanjutnya, pemilihan kernel ditentukan dengan nilai koefisien determinasi $\left(R^{2}\right)$. Batasan nilai $R^{2}$ pada penelitian ini adalah 0,90 , yaitu apabila nilai dari $R^{2} \geqslant 0,90$, maka hasil RVP diterima, dan sebaliknya, apabila nilai $R^{2}<0,90$, maka akan dilakukan proses RVP kembali hingga mendapatkan nilai $R^{2} \geqslant$ 0,90 . Setelah nilai $R^{2}$ didapatkan, tahap selanjutnya adalah mencari nilai galat akar rata-rata kuadrat atau Root Mean Square Error (RMSE) dari parameter optimum yang telah diperoleh dengan membandingkannya terhadap data uji berupa pembacaan estimasi KM oleh HI.

\section{B. Penelitian Tahap 2}

Pada tahap 2, dilakukan pengambilan data historis, lalu dilakukan pemrosesan awal pada data tersebut dengan memisahkan data menjadi data latih dan data uji. Data latih berupa hasil estimasi KK dengan metode peluruhan kapasitas 
sebanyak 49 siklus awal, sedangkan data uji berupa hasil estimasi KK dengan metode peluruhan kapasitas setelah siklus ke-49 hingga akhir dari waktu guna (siklus ke-125). Data latih tersebut digunakan sebagai masukan untuk estimasi KK baterai dengan metode RVP. Pada metode RVP, dicari nilai parameter $\mathrm{C}$, gamma, dan epsilon optimum berdasarkan skor uji rata-rata. Kombinasi parameter RVP dengan skor uji rata-rata tertinggi dipilih untuk diterapkan pada model. Selanjutnya, ketiga kernel diterapkan untuk mengestimasi KK baterai. Ketiga kernel tersebut yaitu kernel linear, polinomial, dan Radial Basis Function (RBF). Dari hasil estimasi masing-masing kernel tersebut selanjutnya dihitung nilai $R^{2}$ dan RMSE.

\section{Kondisi Muatan dan Kondisi Kesehatan Baterai}

KM didefinisikan sebagai rasio kapasitas sisa baterai saat ini dengan kapasitas baterai sebelum pengosongan [6]. Secara matematis, KM baterai dapat diperoleh seperti pada (3), dengan $K M$ menyatakan KM baterai, $C_{r}$ menyatakan kapasitas sisa baterai saat ini dalam $\mathrm{Ah}$, dan $C_{o}$ menyatakan kapasitas baterai pada ketika terisi penuh dalam Ah.

$$
K M=\frac{C_{r}}{C_{o}} .
$$

KK baterai adalah rasio antara kapasitas terukur terhadap kapasitas nominal [14]. Kapasitas terukur adalah kapasitas pada saat terisi penuh sebelum proses pengosongan, sedangkan kapasitas nominal baterai diberikan oleh pabrikan baterai yang menunjukkan kapasitas maksimum dari baterai tersebut ketika masih dalam keadaan baru [4]. Nilai KK baterai menunjukkan derajat degenerasi dari suatu baterai. Secara matematis, estimasi KK baterai dengan metode peluruhan kapasitas dapat diperoleh dengan menggunakan (4), dengan $C_{o}$ menyatakan kapasitas baterai sebelum pengosongan dalam $\mathrm{Ah}$ dan $C_{n}$ menyatakan kapasitas nominal baterai dalam Ah [14], [15].

$$
K K=\frac{C_{o}}{C_{n}} .
$$

\section{Metode Regresi Vektor Pendukung}

Metode RVP merupakan salah satu tipe dari metode Mesin Vektor Pendukung (MVP), yang merupakan salah satu jenis algoritme pembelajaran mesin (machine learning), yang digunakan untuk melakukan analisis untuk mendapatkan pola atau model hubungan sebab-akibat pada data masukan dan keluaran dari suatu sistem dengan proses pembelajaran mesin berdasarkan algoritme pembelajaran berbasis statistik dengan memanfaatkan data latih [5], [16].

MVP bekerja dengan melakukan pemilihan bidang pemisah (boundary plane) pada data yang digunakan. Bidang pemisah adalah permukaan pembagi data yang digunakan pada data multidimensi. Jika terdapat bidang berdimensi $h$, maka bidang pemisah merupakan bidang yang berdimensi $h-1$, sehingga dapat juga disebut hyperplane karena dimensinya bisa lebih dari dua. Bidang pemisah pada MVP linear diilustrasikan pada Gbr. 2 [16]. Persamaan bidang pemisah ditunjukkan pada (5).

$$
y=w x+b
$$

dengan $y$ adalah persamaan bidang pemisah, $w$ adalah pembobotan vektor, dan $b$ adalah intersep. Dari Gbr. 1, galat

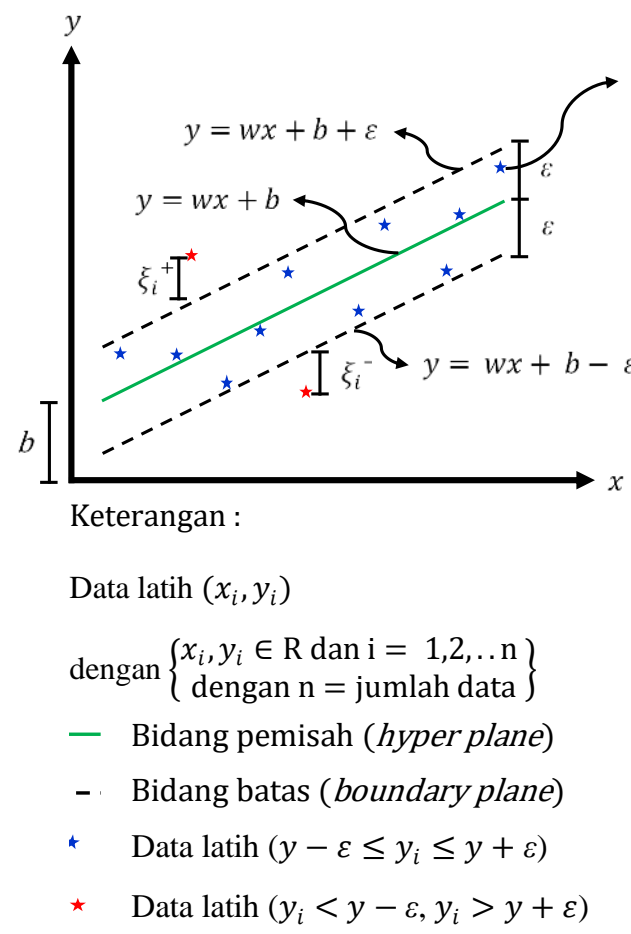

Gbr. 2 Ilustrasi bidang pemisah pada RVP.

antara data latih terhadap bidang pemisah idealnya berada di rentang $\mathrm{y}-\varepsilon$ hingga $\mathrm{y}+\varepsilon$ (tabung $\varepsilon$ ). Hal tersebut dapat dinyatakan dengan fungsi epsilon insensitive loss sebagai berikut [16].

$$
L_{\varepsilon}\left(y_{i}, y\right)=\left\{\begin{array}{l}
0, \quad\left|y_{i}-y\right|<\varepsilon \\
\left|y_{i}-y\right|-\varepsilon, \quad \text { lainnya }
\end{array}\right.
$$

dengan $\varepsilon$ merupakan lebar radius toleransi yang diperbolehkan. Persamaan (4) mengindikasikan bahwa galat dapat diabaikan selama data latih masih berada di dalam tabung $\varepsilon$. Tujuan fungsi epsilon insensitive loss adalah untuk mencari sebuah fungsi yang dapat menyesuaikan data latih dengan galat $\leq \varepsilon$ [17].

Akhirnya, dengan melibatkan fungsi kernel $\kappa\left(x_{i}, x\right)$ untuk mentransformasikan permasalahan ke dimensi yang lebih tinggi agar sistem yang tidak linear dapat ditangani dengan cara biasa, persamaan untuk bidang pemisah dapat dituliskan sebagai (7) sebagai berikut.

$$
y=\sum_{i=1}^{n} \alpha_{i} \cdot \kappa\left(x_{i}, x\right)+b .
$$

Pada metode RVP, terdapat tiga buah tipe kernel yang biasa digunakan. Ketiga kernel tersebut adalah kernel linear, kernel polinomial, dan kernel RBF. Berikut ini adalah bentuk persamaan dari ketiga fungsi kernel tersebut.

Kernel linear:

$$
\kappa\left(x_{i}, x\right)=x_{i}{ }^{T} x .
$$

Kernel polinomial:

$$
\kappa\left(x_{i}, x\right)=\left(x_{i}^{T} x+r\right)^{d} .
$$

Kernel RBF:

$$
\kappa\left(x_{i}, x\right)=\exp \left(-\frac{\left\|x_{i}-x\right\|^{2}}{2 \sigma^{2}}\right)
$$




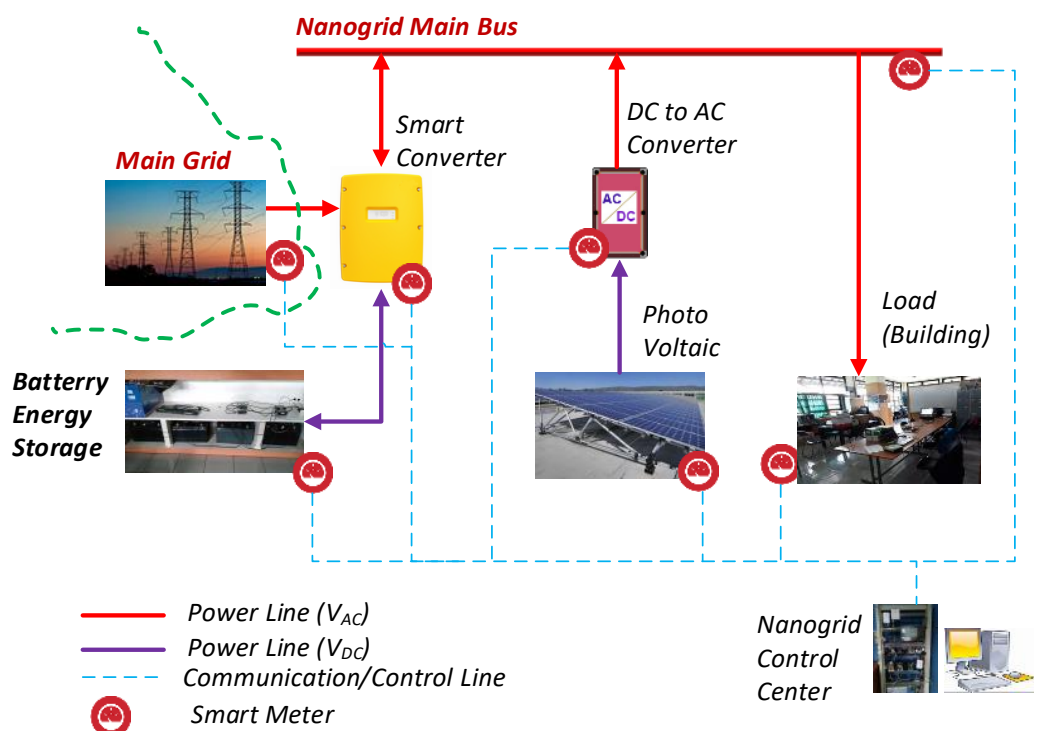

Gbr. 3 Sistem nanogrid di Lab Manajemen Energi TF - ITB.

dengan $r$ adalah intersep, $d$ adalah derajat polinomial, dan $\sigma^{2}$ adalah varians. Untuk pengaplikasiannya pada modul mesin pembelajaran bahasa Python (modul scikit-learn), persamaan matematis RVP tersebut disederhanakan menjadi tiga parameter pemisah (hyper parameter). Ketiga hyper parameter tersebut adalah sebagai berikut [16].

1) Parameter $C$ : Parameter ini ialah representasi dari jangkauan bidang batas untuk mempertimbangkan data latih yang dimiliki. Semakin besar nilai C, model akan berupaya untuk melakukan penyesuaian terhadap lebih banyak data latih. Apabila nilai $\mathrm{C}$ terlalu besar, model akan rentan terhadap gangguan (noise) dan dapat menyebabkan hilangnya sifat umum dari model (overfitting).

2) Parameter Gamma $(\gamma)$ : Parameter ini merupakan inversi dari varians. Nilai $\gamma$ yang rendah mengindikasikan varians yang besar pada data latih, sehingga dua titik dapat dianggap memiliki nilai sama, meskipun berada pada rentang nilai yang signifikan. Sebaliknya, nilai $\gamma$ yang tinggi mengindikasikan varians yang rendah pada data latih.

3) Parameter Epsilon (c): Parameter ini merupakan lebar radius toleransi yang diperbolehkan dari data latih untuk menentukan bidang batas model.

\section{E. Parameter Validasi Model}

Hasil perkiraan model dapat divalidasi dengan koefisien determinasi $\left(R^{2}\right)$ dan galat akar rata-rata kuadrat (RMSE) [18].

1) Koefisien Determinasi $\left(R^{2}\right)$ : Koefisien determinasi merupakan ukuran seberapa baik kemampuan model dalam menerangkan variasi variabel terikat. Nilai $R^{2}$ memiliki rentang 0 hingga 1 , yaitu jika nilai $R^{2}$ mendekati 1 berarti model yang dimiliki dapat mengikuti pola atau variasi variabel terikat (dependent variable) dengan baik. Koefisien determinasi $R^{2}$ dirumuskan pada (11), dengan $y_{i}$ adalah nilai aktual pada sampel ke- $i, \hat{y}_{i}$ adalah nilai estimasi model pada sampel ke- $i, \bar{y}_{i}$ adalah rata-rata nilai aktual, dan $n$ adalah banyaknya sampel.

$$
R^{2}=1-\frac{\sum_{i=1}^{n}\left(y_{i}-\hat{y}_{i}\right)^{2}}{\sum_{i=1}^{n}\left(y_{i}-\bar{y}_{i}\right)^{2}}
$$

Persamaan (11) menggambarkan koefisien determinasi dengan $\sum_{i=1}^{n}\left(y_{i}-\hat{y}_{i}\right)^{2}$ menyatakan jumlah kuadrat sisa (residual sum of square) dan $\sum_{i=1}^{n}\left(y_{i}-\bar{y}_{i}\right)^{2}$ menyatakan jumlah kuadrat total (total sum of square) dari model,

2) RMSE: Galat akar rata-rata kuadrat atau RMSE merupakan akar dari rata-rata galat estimasi yang dikuadratkan. Nilai RMSE dapat dihitung dengan persamaan berikut.

$$
R M S E=\sqrt{\frac{1}{n} \sum_{i=1}^{n}\left(y_{i}-\hat{y}_{i}\right)^{2}}
$$

dengan $y_{i}$ adalah nilai aktual pada sampel ke- $i, \hat{y}_{i}$ adalah nilai estimasi model pada sampel ke- $i$, dan $n$ adalah banyaknya sampel.

\section{F. Konfigurasi Sistem Nanogrid di Lab Manajemen Energi}

Penelitian ini merupakan bagian dari roadmap penelitian yang dilakukan di Laboratorium Manajemen Energi di Program Studi Teknik Fisika ITB. Tema besar dari roadmap penelitian di sini adalah pengembangan sistem nanogrid dan sekaligus penilaian kinerjanya. Umumnya, penelitian tersebut dilaksanakan oleh mahasiswa S1, S2, dan S3 Teknik Fisika yang mempunyai peminatan di bidang manajemen energi dalam rangka penyelesaian tugas akhir. Nanogrid merupakan teknologi yang mengintegrasikan sumber daya energi terdistribusi, seperti turbin angin, panel surya, dan sistem penyimpan energi dengan kapasitas yang kecil (di bawah 10 $\mathrm{kW}$ ). Profil sistem nanogrid pada Laboratorium Manajemen Energi TF - ITB ditunjukkan pada Gbr. 3 [2].

Berdasarkan Gbr. 3, dapat diketahui bahwa sumber energi dari sistem nanogrid pada Laboratorium Manajemen Energi TF - ITB berasal dari PLTS sebagai sumber energi utama, jaringan 


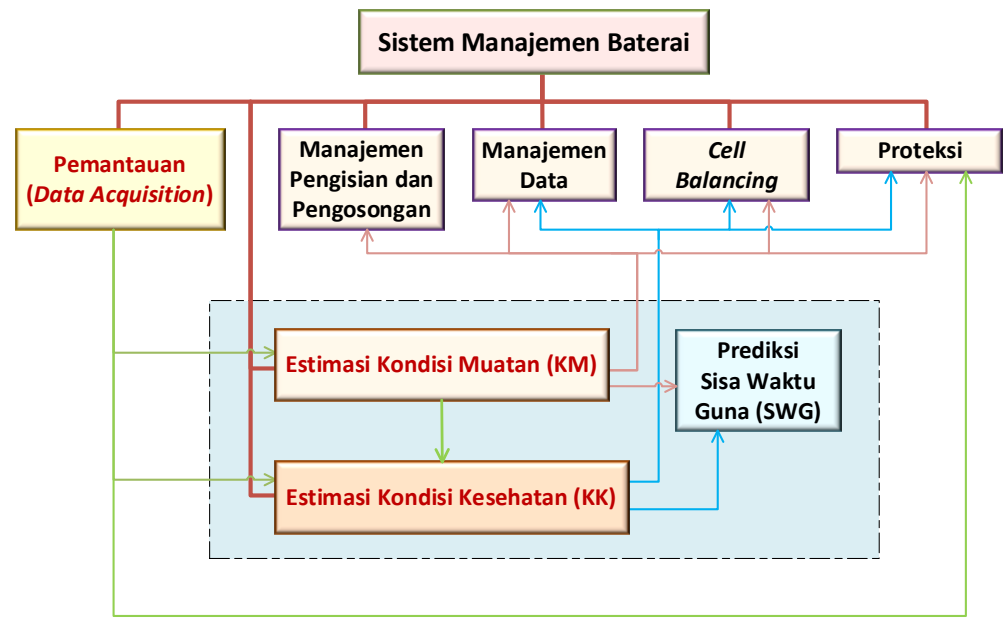

Gbr. 4 Fitur-fitur Sistem Manajemen Baterai (SMB).

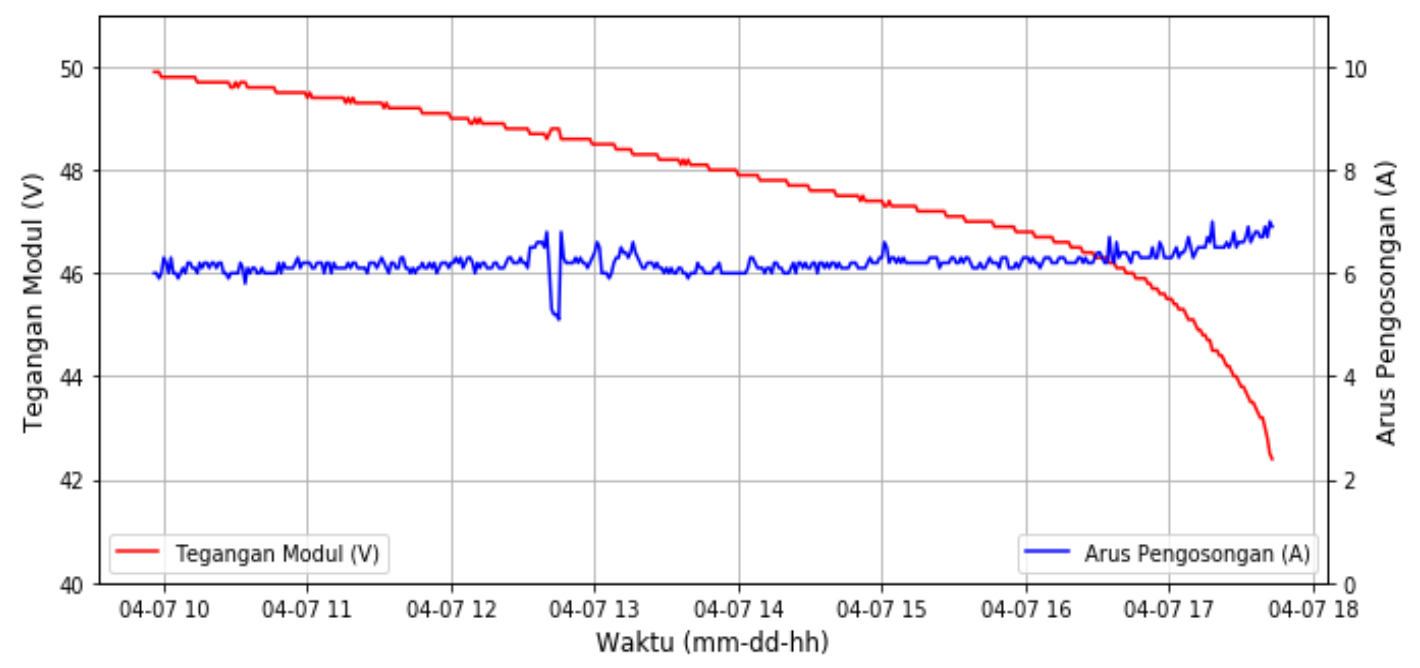

Gbr. 5 Tegangan modul dan arus pengosongan terhadap waktu.

listrik PLN sebagai sumber energi listrik cadangan, dan baterai sebagai sistem penyimpan energi listrik.

\section{G. Sistem Manajemen Baterai}

SMB di sini berfungsi untuk melindungi baterai dari kerusakan dan memelihara baterai pada saat kondisi operasi dengan mengintegrasikan salah satu atau beberapa fitur, seperti sistem pengawasan, proteksi, manajemen pengisian dan pengosongan, diagnosis, serta manajemen data. Secara umum, fitur-fitur SMB ditunjukkan pada Gbr. 4.

\section{HASIL DAN PEMBAHASAN}

\section{A. Estimasi Kondisi Muatan Baterai}

Data yang diambil untuk estimasi KM baterai adalah hasil pengukuran tegangan modul baterai, arus pengosongan baterai, temperatur modul baterai, dan pembacaan KM baterai oleh $\mathrm{HI}$ yang dilakukan pada tanggal 7 April 2019 pukul 09.56-17.43 WIB.

Pembuatan model estimasi KM baterai dimulai dengan melakukan proses pengosongan baterai VRLA pada kondisi jaringan PLN dan sistem PLTS mati, sehingga suplai energi hanya berasal dari baterai. Proses pengosongan baterai dilakukan pada arus pengosongan rata-rata 6,2 A dengan waktu pencacahan 1 menit selama 7 jam 48 menit, sehingga total data pengukuran yang diperoleh sebanyak 468 data. Data pengukuran yang diambil pada proses pengosongan tersebut adalah tegangan modul baterai, arus pengosongan baterai, temperatur modul baterai, dan pembacaan KM baterai oleh $\mathrm{HI}$.

Gbr. 5 memperlihatkan tegangan modul baterai dan arus pengosongan terhadap waktu pada saat proses pengosongan baterai. Rentang tegangan pada proses pengosongan tersebut berada pada $42,4 \mathrm{~V}$ hingga $50,4 \mathrm{~V}$, sedangkan rentang arus pengosongan pada saat proses pengosongan berada pada 5,1 $\mathrm{A}$ hingga $7 \mathrm{~A}$.

Estimasi KM menggunakan metode CC dilakukan dengan pertama kali mengisi baterai (charge) hingga penuh, dilanjutkan dengan proses pengosongan (discharge) dengan kecepatan tertentu. Sepanjang proses pengosongan, parameterparameter baterai, yaitu tegangan $(V)$, arus $(I)$, dan temperatur (T) direkam dengan cermat. Tahap selanjutnya adalah mengestimasi KM baterai dengan metode $\mathrm{CC}$ menggunakan (2). Perhitungan estimasi KM baterai dengan metode $\mathrm{CC}$ 


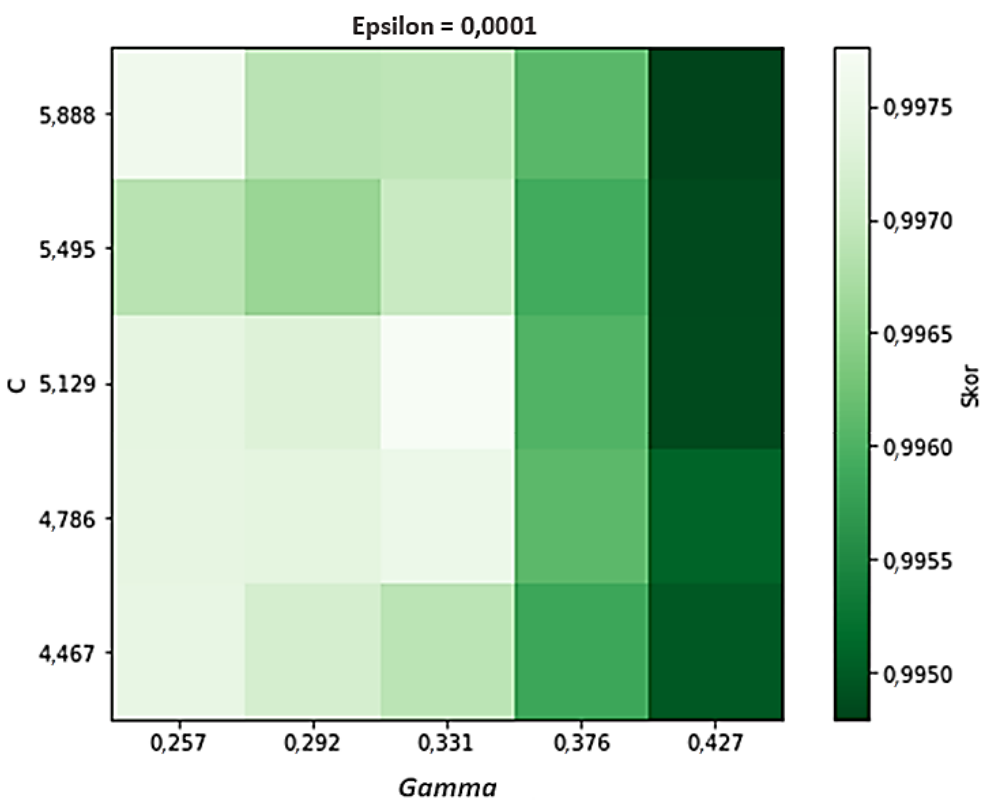

Gbr. 6 Penentuan parameter estimasi KM dengan grid search.

dilakukan menggunakan bahasa pemrograman Python dengan bantuan perangkat lunak Jupyter. Untuk membatasi jumlah halaman pada makalah ini, hasil estimasi dengan metode CC ini di-plot dalam satu gambar yang sama dengan hasil estimasi menggunakan metode RVP.

Tahap selanjutnya adalah melakukan estimasi KM baterai dengan metode RVP. Pada tahap ini, digunakan data latih berupa data pembacaan KM oleh HI dan hasil estimasi KM dengan metode CC. Diketahui ada tiga parameter RVP yang akan sangat menentukan tingkat akurasi model yang dihasilkan, yaitu parameter C, gamma, dan epsilon. Nilai parameter yang tidak tepat akan menghasilkan model estimasi yang buruk. Untuk dapat menentukan parameter terbaik, digunakan modul grid search yang ada di Python. Hasil dari grid search berupa skor uji rata-rata yang selanjutnya dapat disebut skor parameter, dengan rentang 0 hingga 1 . Semakin tinggi skor yang diperoleh, semakin baik parameter tersebut mendefinisikan model yang dimiliki.

Hasil penentuan parameter optimum RVP pada estimasi KM baterai menggunakan modul grid search diperlihatkan pada Gbr. 6. Pada gambar ini, semakin putihnya sel pada grid search menjadi indikasi bahwa skor parameter semakin tinggi. Terlihat bahwa parameter RVP hasil validasi tersebut memiliki nilai optimum pada $\mathrm{C}=5,129$, gamma $=0,331$, dan epsilon = 0,0001 , dengan skor sebesar 0,9978. Untuk memvalidasi bahwa nilai epsilon yang didapat optimum, nilai $\mathrm{C}$ dan gamma dibuat konstan, sedangkan nilai epsilon dinaikkan dan diturunkan hingga didapatkan skor tertinggi. Hasil validasi parameter epsilon optimum disajikan pada Tabel I.

Berdasarkan Tabel I, tampak bahwa nilai epsilon berbanding terbalik dengan skor. Semakin kecil nilai epsilon, semakin besar nilai skor parameter. Pada model 4 terlihat bahwa skor turun dari 0,9978 menjadi 0,9976. Hal ini mengindikasikan bahwa model optimum adalah model sebelumnya, yaitu model 3 , dengan nilai epsilon sebesar 0,0001, sehingga parameter optimum untuk estimasi KM baterai dengan RVP adalah model
TABEL I

HASIL VALIDASI PARAMETER ESTIMASI KM DENGAN GRID SEARCH

\begin{tabular}{|c|c|c|c|c|c|}
\hline \multirow{2}{*}{ Model } & \multicolumn{3}{|c|}{ Parameter } & \multirow{2}{*}{ Skor } & \multirow{2}{*}{ Keterangan } \\
\cline { 2 - 4 } & $\boldsymbol{C}$ & $\boldsymbol{\gamma}$ & $\boldsymbol{\varepsilon}$ & & \\
\hline 1 & 5,129 & 0,331 & 0,01 & 0,6137 & - \\
\hline 2 & 5,129 & 0,331 & 0,001 & 0,9907 & - \\
\hline 3 & 5,129 & 0,331 & 0,0001 & 0,9978 & Optimum \\
\hline 4 & 5,129 & 0,331 & 0,00001 & 0,9976 & - \\
\hline
\end{tabular}

TABEL II

VALIDASI METODE ESTIMASI KM BATERAI

\begin{tabular}{|c|c|c|}
\hline Metode & $\boldsymbol{R}^{\mathbf{2}}$ & RMSE \\
\hline CC & 0,9268 & 0,0220 \\
\hline RVP & 0,9991 & 0,0024 \\
\hline
\end{tabular}

3 dengan nilai $\mathrm{C}=5,129$, gamma $=0,331$, dan epsilon $=0,0001$. Selanjutnya, hasil parameter model 3 digunakan untuk melakukan estimasi KM baterai dengan metode RVP.

Selanjutnya, hasil estimasi KM baterai dengan metode RVP dan hasil estimasi dengan metode $\mathrm{CC}$ ini di-plot pada satu grafik yang sama yang ditunjukkan pada Gbr. 7. Pada grafik ini ditampilkan juga grafik KM yang terbaca pada modul HI untuk dibandingkan.

Langkah berikutnya adalah memvalidasi hasil estimasi KM dengan metode CC dan metode RVP menggunakan besaran $R^{2}$ dan RMSE, yang hasilnya diperlihatkan pada Tabel II. Dari sini dapat dikonfirmasi bahwa estimasi KM dengan metode SVR memberikan hasil yang lebih baik dibandingkan dengan metode CC.

Hasil estimasi KM baterai dengan metode RVP pada penelitian ini selanjutnya dibandingkan dengan hasil estimasi KM baterai dengan metode serupa pada penelitian sebelumnya [13]. Tabel III memperlihatkan perbandingan hasil estimasi KM baterai dengan penelitian sebelumnya. Dari tabel ini terlihat bahwa metode RVP pada penelitian ini menghasilkan nilai RMSE empat kali lebih kecil dibandingkan dengan 


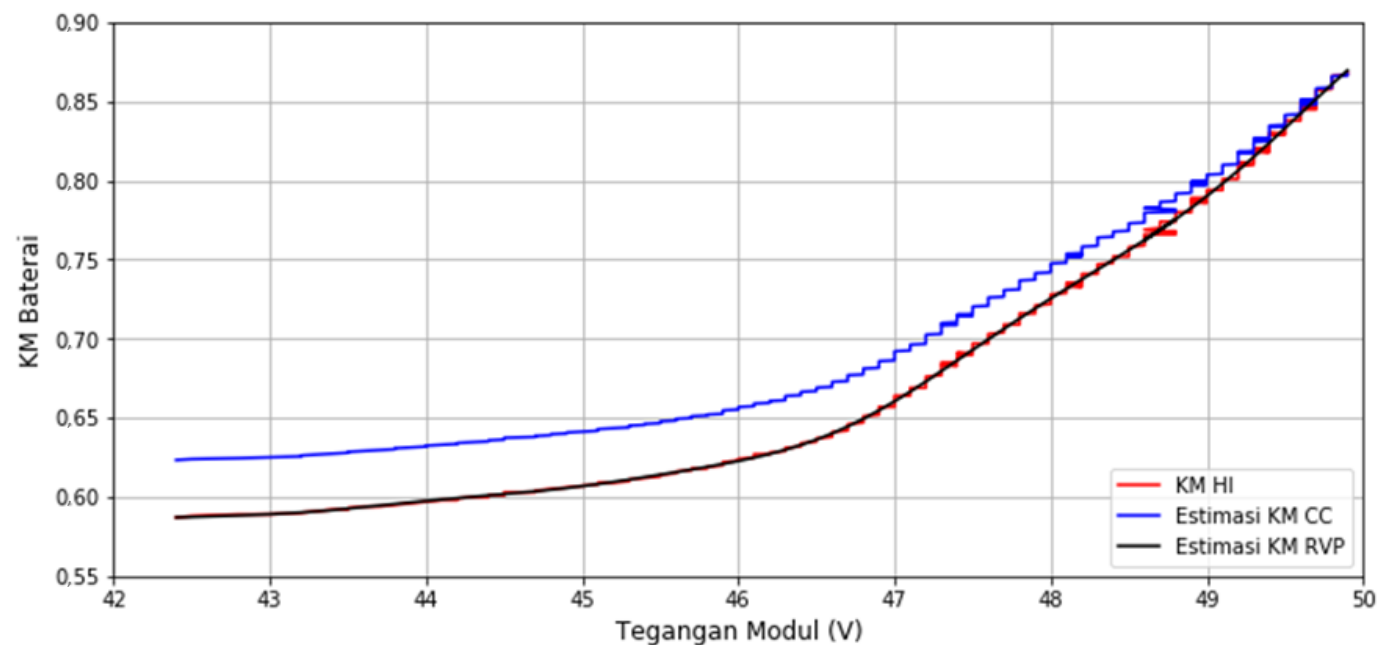

Gbr. 7 Estimasi KM baterai dengan metode RVP dibandingkan dengan metode CC dan hasil pembacaan modul HI.

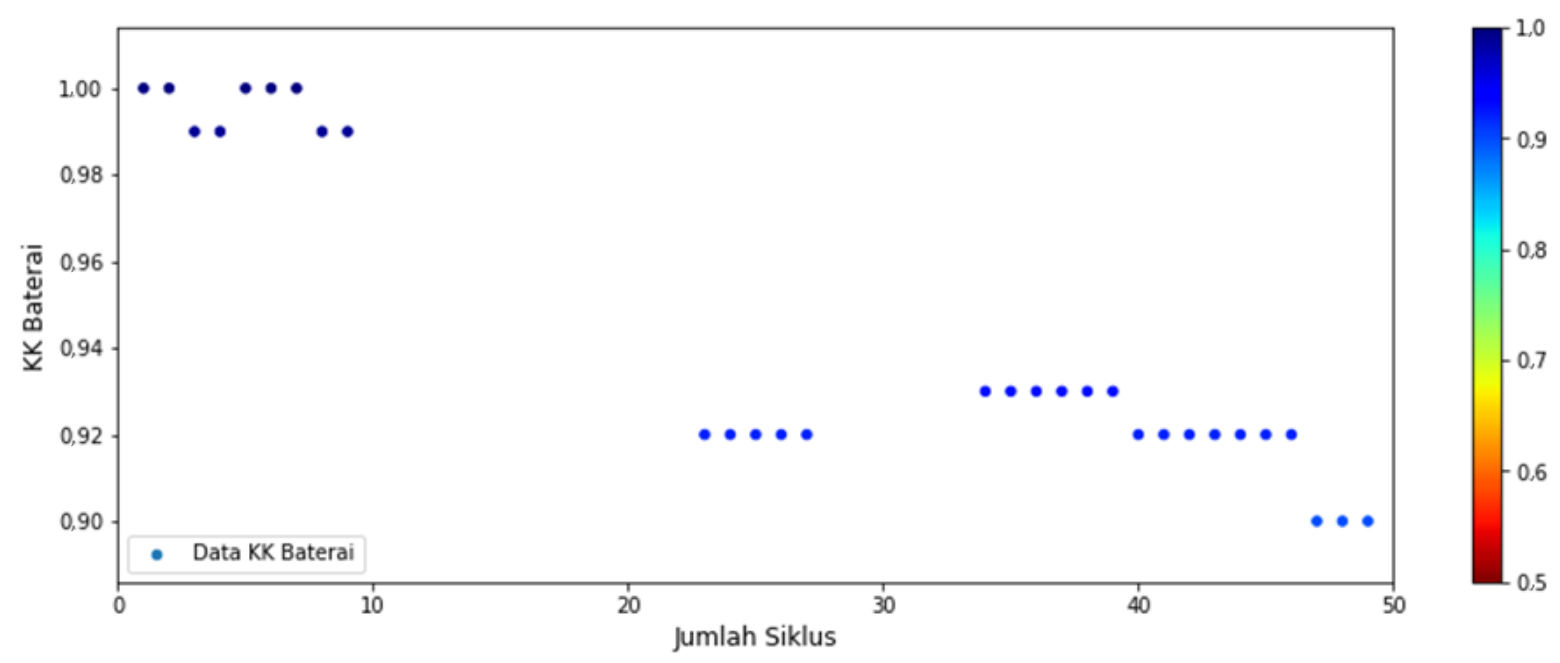

Gbr. 8 Data latih KK baterai.

TABEL III

PERBANDINGAN HASIL ESTIMASI KM BATERAI

\begin{tabular}{|c|c|c|c|c|}
\hline Penelitian & Tahun & Jenis Baterai & Metode & RMSE \\
\hline$[13]$ & 2016 & VRLA & RVP & 0,0098 \\
\hline Penelitian ini & 2019 & VRLA & RVP & 0,0024 \\
\hline
\end{tabular}

metode yang sama pada penelitian sebelumnya. Hal ini dikarenakan pada penelitian sebelumnya, penentuan parameter optimum RVP tidak menggunakan metode grid search, tetapi menggunakan pencarian manual (manual search) untuk memperoleh hasil RMSE minimum.

\section{B. Estimasi Kondisi Kesehatan Baterai}

Data yang diambil untuk estimasi KK baterai adalah pembacaan KK baterai oleh $\mathrm{HI}$ dari awal instalasi pada tanggal 18 Februari 2014 hingga akhir waktu guna pada tanggal 9 Februari 2018. Model estimasi KK baterai dilakukan pada data latih sebanyak 49 siklus yang terdiri atas tiga puluh siklus dengan nilai KK hasil perhitungan metode peluruhan kapasitas dan sembilan belas siklus sisanya bernilai kosong. Siklus kosong tersebut terbagi menjadi dua bagian, yaitu sebanyak tiga belas siklus kosong akibat perbaikan server dan enam siklus kosong akibat terjadinya kegagalan Modbus Remote Terminal Unit (RTU). Data latih untuk estimasi KK ditunjukkan pada Gbr. 8. Selanjutnya, dilakukan estimasi menggunakan metode RVP berdasarkan nilai KK dari tiga puluh siklus yang ada.

Estimasi KK baterai dengan metode RVP dilakukan dengan tiga kernel yang berbeda, yaitu kernel linear, polinomial, dan RBF. Ketiga kernel tersebut diterapkan kemudian dipilih salah satu yang paling optimum untuk digunakan pada estimasi KK baterai. Penentuan parameter RVP optimum dilakukan dengan grid search yang hasilnya ditunjukkan pada Gbr. 9. Gambar tersebut menunjukkan penentuan parameter optimum algoritme RVP dengan kernel polinomial dan RBF untuk estimasi KK dengan metode grid search. Terlihat bahwa parameter RVP hasil validasi tersebut memiliki nilai optimum pada $\mathrm{C}=$ 141.252, gamma $=1,02$ e-05, dan epsilon $=0,009$, dengan skor sebesar 0,7933. Skor di sini merepresentasikan nilai parameter dalam mendefinisikan model yang dimiliki. Nilai skor berada pada rentang 0 hingga 1 . Semakin tinggi skor yang diperoleh, semakin baik parameter tersebut mendefinisikan model yang dimiliki. 


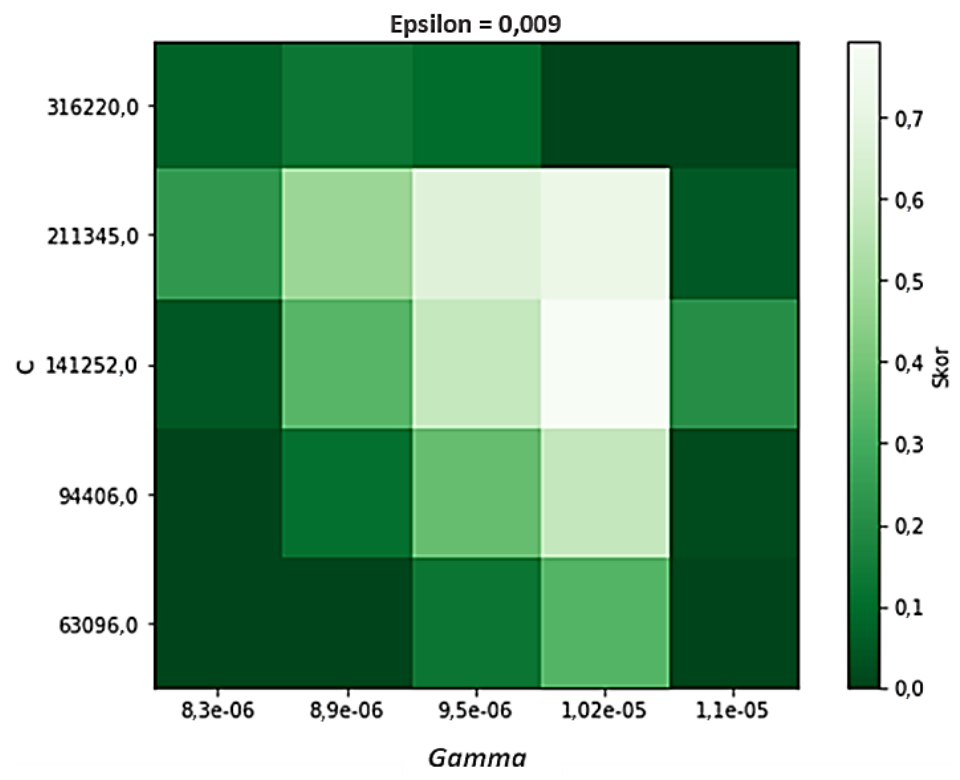

Gbr. 9 Penentuan parameter estimasi KK dengan grid search.

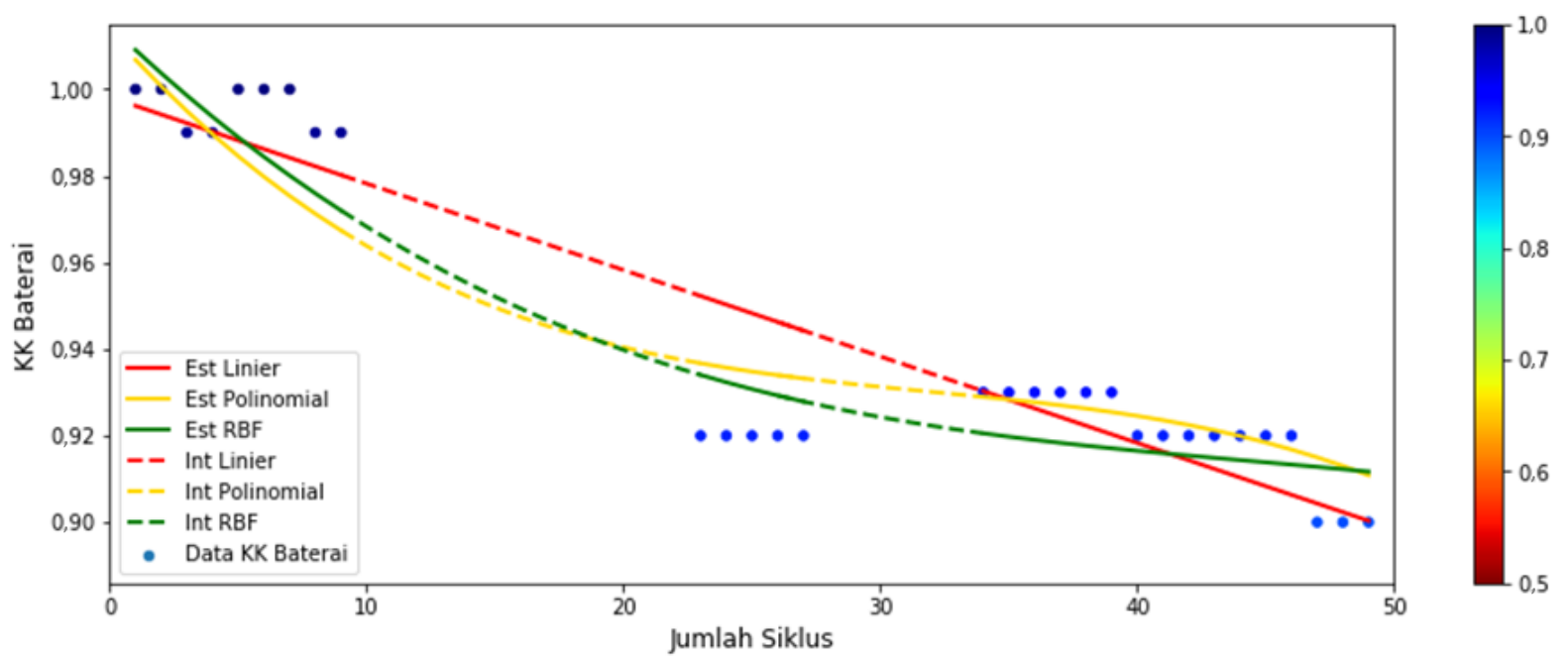

Gbr. 10 Hasil estimasi KK baterai pada data latih dan hasil interpolasinya pada data yang kosong.

TABEL IV

PARAMETER ESTIMASI KK BATERAI DENGAN RVP

\begin{tabular}{|l|c|c|c|c|c|c|}
\hline \multirow{2}{*}{ Kernel } & \multicolumn{7}{|c|}{ Parameter } \\
\cline { 2 - 7 } & $\boldsymbol{C}$ & $\boldsymbol{\gamma}$ & $\boldsymbol{\varepsilon}$ & $\boldsymbol{w}$ & $\boldsymbol{b}$ & $\boldsymbol{d}$ \\
\hline Linear & - & - & - & $-0,001996$ & 0,996172 & - \\
\hline Polinomial & 141252 & $1,02 \mathrm{e}-05$ & 0,009 & - & - & 3 \\
\hline RBF & 141252 & $1,02 \mathrm{e}-05$ & 0,009 & - & - & - \\
\hline
\end{tabular}

Hasil parameter optimum tersebut selanjutnya diterapkan untuk mengestimasi KK baterai pada kernel RBF dan kernel polinomial derajat tiga. Ketiga kernel tersebut selanjutnya digunakan untuk melakukan interpolasi KK baterai pada tiga belas siklus kosong akibat perbaikan. Parameter hasil estimasi KK baterai dengan tiga kernel tersebut diperlihatkan pada Tabel IV.

Pada kernel linear, didapatkan persamaan -0,001996x + 0,996172 dengan $x$ menyatakan jumlah siklus. Nilai $-0,001996$ menyatakan pembobotan vektor $(w)$ yang pada kernel tersebut bernilai negatif. Hal ini berarti bahwa KK baterai berbanding terbalik dengan jumlah siklus. Sesuai dengan penelitian sebelumnya [4], semakin banyak jumlah siklus, semakin turun nilai KK baterai, dengan penurunan sebesar 0,001996 untuk kenaikan setiap satu siklus. Nilai 0,996172 menyatakan intersep $(b)$ yang pada siklus ke-0, nilai KK baterai adalah 0,996172 .

Gbr. 10 menunjukkan hasil estimasi KK baterai dengan kernel linear, polinomial, dan RBF, sekaligus hasil interpolasinya. Selanjutnya, hasil estimasi KK baterai pada masing-masing kernel tersebut divalidasi dengan menghitung nilai $R^{2}$ dan RMSE. Hasil validasi model untuk masing-masing kernel ditunjukkan pada Tabel V.

Berdasarkan Tabel V, diketahui bahwa diperoleh nilai $R^{2}$ untuk kernel linear sebesar 0,8533, kernel polinomial sebesar 0,8968, dan kernel RBF sebesar 0,9081. Dari tabel yang sama dapat dilihat bahwa nilai RMSE terkecil dimiliki oleh kernel RBF, yaitu sebesar 0,0108, sedangkan pada kernel linear 
TABEL V

VALIDASI KERNEL RVP PADA ESTIMASI KK BATERAI

\begin{tabular}{|l|c|c|c|}
\hline Kernel & $\boldsymbol{R}^{\mathbf{2}}$ & RMSE & Keterangan \\
\hline Linear & 0,8533 & 0,0136 & - \\
\hline Polinomial & 0,8968 & 0,0114 & - \\
\hline RBF & 0,9081 & 0,0108 & Optimum \\
\hline
\end{tabular}

diperoleh nilai RMSE sebesar 0,0136 dan pada kernel polinomial diperoleh nilai RMSE sebesar 0,0114. Dari ketiga kernel tersebut, kernel RBF memberikan nilai $R^{2}$ paling tinggi dengan RMSE terkecil. Hal ini dikarenakan kernel RBF memiliki kemampuan yang baik dalam kasus regresi linear maupun nonlinear

\section{KESIMPULAN}

\section{A. Kesimpulan}

Estimasi KM dan KK sangat penting dalam rangka optimalisasi penggunaan baterai, terlebih lagi ketika baterai digunakan sebagai sistem penyimpan energi cadangan pada sistem nanogrid. Namun, yang menjadi permasalahan adalah tidak ada peralatan instrumentasi yang dapat secara langsung mengukur kedua besaran tersebut. Tujuan dari penerapan regresi RVP dengan bermacam-macam kernel adalah agar hasil regresi dapat dijadikan model untuk mengestimasi KM dan KK baterai yang tidak dapat diukur secara langsung dengan menggunakan indikator-indikator lain yang dapat diukur dengan peralatan/instrumentasi pengukuran yang tersedia.

Modul mesin pembelajaran Python memungkinkan implementasi RVP dengan berbagai jenis kernel, di antaranya kernel linear, kernel polinomial, dan kernel RBF yang digunakan dalam makalah ini. Pengujian yang dilakukan dengan menggunakan modul grid search ini menunjukkan bahwa kinerja terbaik diperoleh ketika digunakan kernel RBF.

Kerugian dari metode $\mathrm{CC}$ adalah hasil yang sangat bergantung pada keakuratan sensor. Sensor yang tidak akurat akan menyebabkan terjadinya akumulasi kesalahan karena sifatnya yang open-loop.

Data penelitian menunjukkan bahwa tingkat kesehatan baterai mengalami penurunan dari waktu ke waktu seiring dengan terjadinya proses pengosongan (discharging) dan pengisian (charging) pada baterai. Dengan melakukan estimasi KK baterai, dapat diketahui baterai masih layak dioperasikan atau sudah perlu untuk diganti dengan yang baru.

Berdasarkan penelitian ini, dapat disimpulkan bahwa model estimasi KM baterai dengan RVP memiliki tingkat akurasi yang lebih baik dibandingkan dengan metode CC, seperti terlihat pada Tabel II, yaitu nilai $R^{2}$ sebesar 0,9991 dan nilai RMSE sebesar 0,0024. Sementara itu, untuk model estimasi KK dengan metode RVP memiliki nilai $R^{2}$ sebesar 0,9081 dan nilai RMSE sebesar 0,0108 .

\section{B. Prospek Penelitian Lanjutan}

Untuk kelanjutan penelitian, ada beberapa kemungkinan yang dapat dilakukan, seperti melakukan penelitian parameter kinerja baterai yang lainnya, yaitu prediksi SWG, menyelidiki lebih jauh lagi pengaruh temperatur terhadap KM, KK, dan
SWG, dan lebih jauh lagi meneliti pengaruh SMB, seperti pengontrolan kecepatan pengisian dan pengosongan terhadap keandalan sistem nanogrid. Sebagai perbandingan, dapat juga digunakan metode sistem pembelajaran yang lain, yaitu ANN atau deep learning untuk diterapkan pada data yang ada pada penelitian ini.

\section{REFERENSI}

[1] M.M. Rahman, A.O. Oni, E. Gemechu, dan A. Kumar, "Assessment of Energy Storage Technologies: A Review," Energy Convers. Manag., Vol. 223, hal. 113295, 2020

[2] D. Widjajanto, E. Leksono, dan A. Widyotriatmo, "Nanogrid Reliability Assessment Study Using Loss of Load Expectation," Int. J. Renew. Energy Res., Vol. 9, No. 4, hal. 2040-2052, 2019.

[3] S. Petrovic, Battery Technology Crash Course: A Concise Introduction, Cham, Switzerland: Springer, 2011.

[4] J. Jung, L. Zhang, dan J. Zhang, Lead-Acid Battery Technologies Fundamentals, Materials and Applications, Boca Raton, USA: CRC Press, 2016.

[5] C. Vidal, P. Malysz, P. Kollmeyer, dan A. Emadi, "Machine Learning Applied to Electrified Vehicle Battery State of Charge and State of Health Estimation: State-of-the-Art," IEEE Access, Vol. 8, hal. 52796-52814, 2020.

[6] M. Danko, J. Adamec, M. Taraba, dan P. Drgona, "Overview of Batteries State of Charge Estimation Methods," Transp. Res. Procedia, Vol. 40, hal. 186-192, 2019.

[7] Y. Wang, J. Tian, Z. Sun, Z.L. Wang, R. Xu, M. Li, dan Z. Chen, “A Comprehensive Review of Battery Modeling and State Estimation Approaches for Advanced Battery Management Systems," Renew. Sustain. Energy Rev., Vol. 131, hal. 110015, 2020.

[8] P. Křivík, "Methods of SoC Determination of Lead Acid Battery," $J$. Energy Storage, Vol. 15, hal. 191-195, 2018.

[9] G.A. Trinandana, A.W. Pratama, E. Prasetyono, dan D.O. Anggriawan, "Real Time State of Charge Estimation for Lead Acid Battery Using Artificial Neural Network," Proc. - 2020 Int. Semin. Intell. Technol. Its Appl. (ISITIA 2020), 2020, hal. 363-368.

[10] V. Surendar, V. Mohankumar, S. Anand, dan V.D. Prasanna, "Estimation of State of Charge of a Lead Acid Battery Using Support Vector Regression," Procedia Technol., Vol. 21, hal. 264-270, 2015.

[11] S. Boulmrharj, R. Ouladsine, Y. NaitMalek, M. Bakhouya, K. Zine-dine, M. Khaidar, dan M. Siniti, "Online Battery State-of-Charge Estimation Methods in Micro-Grid Systems," J. Energy Storage, Vol. 30, hal. 1-18, 2020.

[12] S.C. Huang, K.H. Tseng, J.W. Liang, C.L. Chang, dan M.G. Pecht, “An Online SOC and SOH Estimation Model for Lithium-Ion Batteries," Energies, Vol. 10, No. 4, hal. 1-18, 2017.

[13] R.H. Saputra, "Estimasi SOC dan SOH pada Sistem Baterai dengan Metode Support Vector Machine.” Institut Teknologi Bandung, Bandung, Indonesia, Laporan Penelitian, hal. 1-10, 2016.

[14] B. Gou, Y. Xu, dan X. Feng, "State-of-Health Estimation and RemainingUseful-Life Prediction for Lithium-Ion Battery Using a Hybrid DataDriven Method," IEEE Trans. Veh. Technol., Vol. 69, No. 10, hal. 10854 $10867,2020$.

[15] A. Guha dan A. Patra, "State of Health Estimation of Lithium-Ion Batteries Using Capacity Fade and Internal Resistance Growth Models," IEEE Trans. Transp. Electrif., Vol. 4, No. 1, hal. 135-146, 2017.

[16] A. Nefedov (2016) "Support Vector Machines: A Simple Tutorial," [Online], https://sustech-cs-courses.github.io/IDA/materials/ Classification/SVM_tutorial.pdf, tanggal akses: 25-Jun-2019.

[17] S. Shokri, M.T. Sadeghi, M.A. Marvast, dan S. Narasimhan, "Improvement of the Prediction Performance of a Soft Sensor Model Based on Support Vector Regression for Production of Ultra-Low Sulfur Diesel," Pet. Sci., Vol. 12, No. 1, hal. 177-188, 2015.

[18] R.J. Hyndman (2014) "Measuring Forecast Accuracy," [Online] https://robjhyndman.com/papers/forecast-accuracy.pdf, tanggal akses 25-Jun-2019. 